*ak RMIS View/Frint Document Cover Sheet tow

This document was retrieved from the Documentation and Records Manaqement (DRM) ISEARCH System. It is intended for Information only and may not be the most recent or updated version. Contact a Document Service Center (see Hanford Info for locations) if you need additional retrieval information.

Accession \#: D196093663

Document \#: SD-WM-SDS-008

Title/Desc:

PAMS PHOTO IMAGE RETRIEVAL PROTOTYPE SYSTEM REQUIREMENTS SPEC

Pages: 19 


\begin{tabular}{|c|c|c|}
\hline $\begin{array}{l}\text { 2. To: (Receiving organization) } \\
\text { Distribution }\end{array}$ & $\begin{array}{l}\text { 3. From: coriginating organization) } \\
\text { Media Systems } \\
\text { Application/Media Management } \\
\text { Systems/BCSR }\end{array}$ & 4. Related EDT No.: \\
\hline $\begin{array}{l}\text { 5. Proj./Prog./Dept./Div.: } \\
\text { Engineering/Interim } \\
\text { Stabilization Project/Tank } \\
\text { Farm Transition Projects }\end{array}$ & 6. Cog. Engr.: & $\begin{array}{l}\text { 7. Purchase Order No.: } \\
\text { N/A }\end{array}$ \\
\hline \multirow{2}{*}{\multicolumn{2}{|c|}{ 8. Originator Remarks: }} & $\begin{array}{l}\text { 9. Equip./Component No.: } \\
\text { N/A }\end{array}$ \\
\hline & & $\begin{array}{c}\text { 10. System/Bldg./Facility: } \\
\text { VIDON }\end{array}$ \\
\hline \multirow[t]{3}{*}{ 11. Receiver Remarks: } & & $\begin{array}{r}\text { 12. Major Assm. Dwg. No.: } \\
\text { N/A }\end{array}$ \\
\hline & & $\begin{array}{l}\text { 13. Permit/Permit Application No.: } \\
\text { N/A }\end{array}$ \\
\hline & & 14. Required Response Date: \\
\hline
\end{tabular}

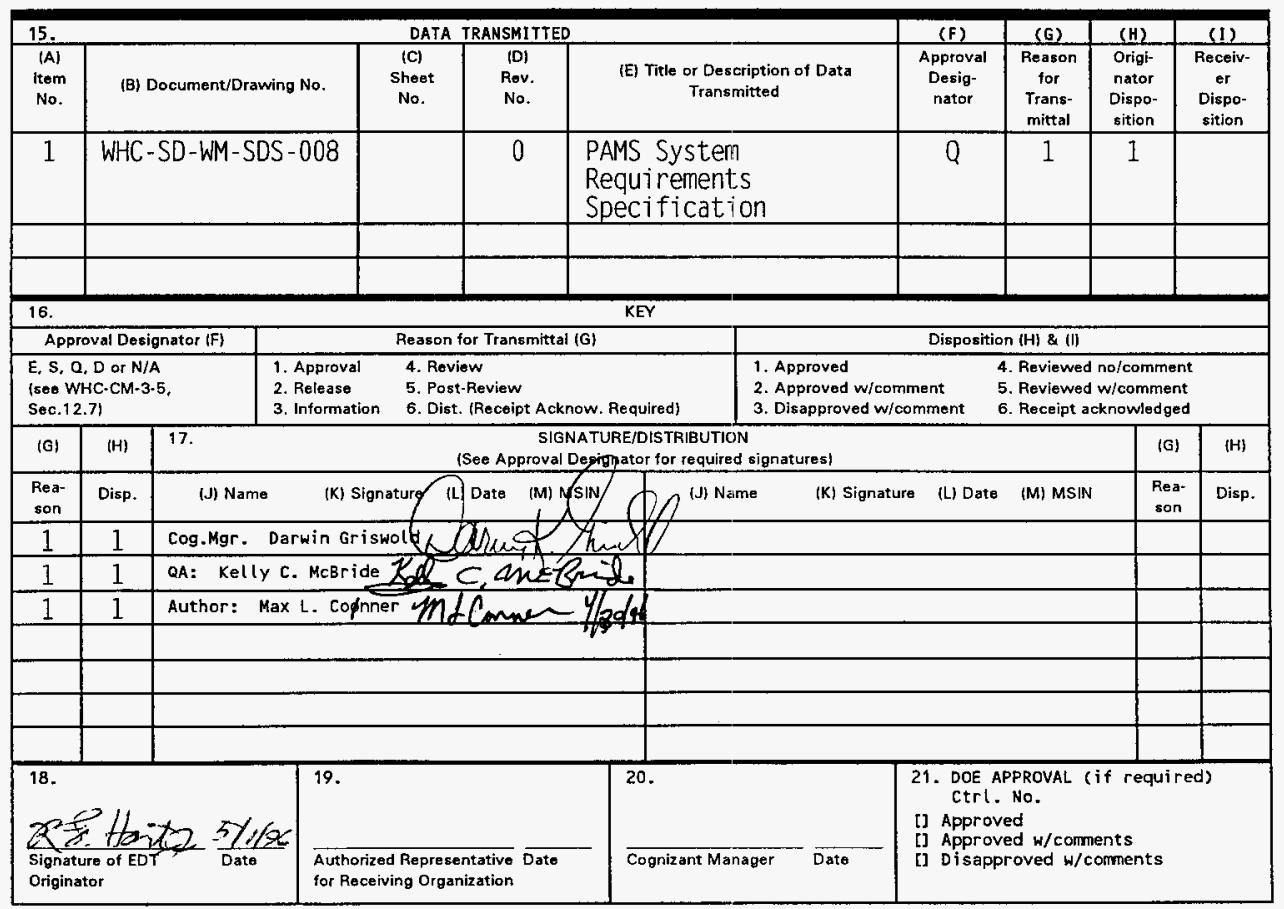




\title{
PAMS PHOTO IMAGE RETRIEVAL PROTOTYPE System Requirements Specification
}

\author{
Max L. Conner \\ Westinghouse Hanford Company/Boeing Computer Services Richland \\ Richland, WA 99352 \\ U.S. Department of Energy Contract DE-AC06-87RL10930 \\ EDT/ECN: 615702 \\ Org Code: 67100 \\ B\&R Code: YN0100000 \\ UC: 2030 \\ Charge Code: MP500 \\ Total Pages: 17
}

Key Words: System, Requi rements

Abstract:

The PAMS Photo Imaging subsystem will provide the means of capturing low resolution digital images from Photography's negative files and associating the digital images with a record in the PAMS photo database. The digital images and key photo identification information will be accessible to HAN users to assist in locating and identifying specific photographs. After identifying desired photographs, users may request photo prints or high resolution digital images directly from Photography.

Trademarks :

AREV is a trademark of Revelation Technologies.

SQL Server is a trademark of Microsoft Corporation.

Windows is a trademark of Microsoft Corporation.

TRADEMARK DISCLAIMER. Reference herein to any specific comercial product, process, or service by trade name, trademark, manufacturer, or otherwise, does not necessarily constitute or imply its endorsement, recommendation, or favoring by the United States Government or any agency thereof or its contractors or subcontractors.

Printed in the United States of America. To obtain copies of this document, contact: WHC/BCS Document Control Services, P.O. Box 1970, Mailstop H6-08, Richland WA 99352, Phone (509) 372-2420; Fax (509) 376-4989.
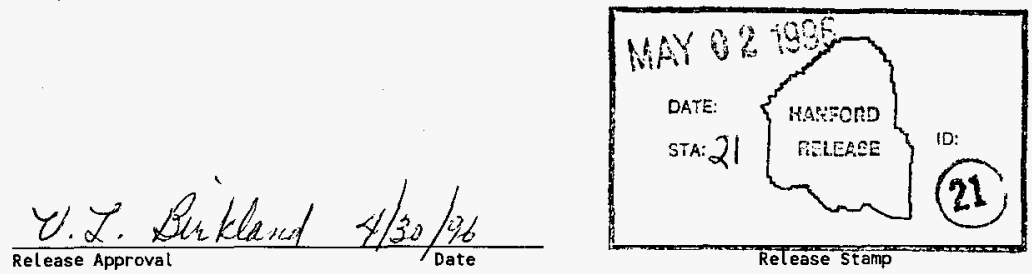

\section{Approved for Public Release}




\title{
PAMS PHOTO IMAGE RETRIEVAL PROTOTYPE
}

\section{SYSTEM REQUIREMENTS SPECIFICATION}

\author{
Prepared By: \\ Max L. Conner \\ IRM, hIMACS Systems Development
}




\section{TABLE OF CONTENTS}

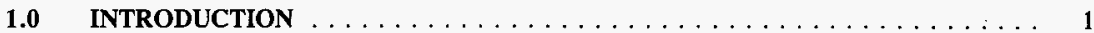

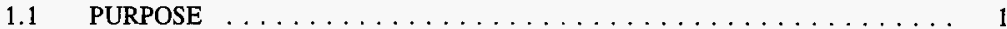

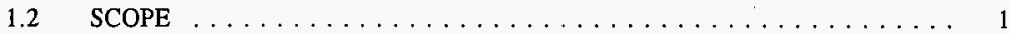

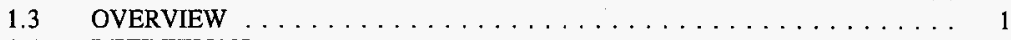

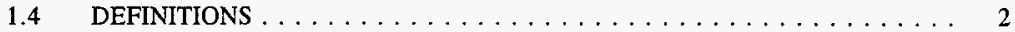

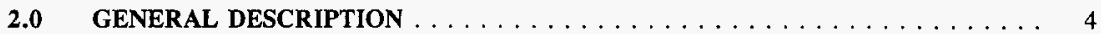

2.1. PRODUCT FUNCTIONS $\ldots \ldots \ldots \ldots \ldots \ldots \ldots \ldots \ldots \ldots$

2.2 USER CHARACTERISTICS $\ldots \ldots \ldots \ldots \ldots \ldots \ldots \ldots \ldots \ldots$

3.0 SPECIFIC REQUIREMENTS $\ldots \ldots \ldots \ldots \ldots \ldots \ldots \ldots \ldots \ldots \ldots$

3.1 FUNCTIONAL REQUIREMENTS $\ldots \ldots \ldots \ldots \ldots \ldots \ldots \ldots \ldots, 6$

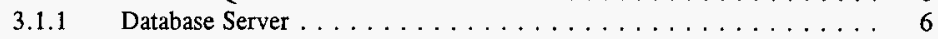

3.1.2 Stored Image Attributes $\ldots \ldots \ldots \ldots \ldots \ldots \ldots \ldots \ldots \ldots$

3.1.3 Image Capture Workstation . . . . . . . . . . . . 7

3.1.4 Image Capture $\ldots \ldots \ldots \ldots \ldots \ldots \ldots \ldots \ldots \ldots \ldots \ldots \ldots$

3.1.5 Retrieve Workstation $\ldots \ldots \ldots \ldots \ldots \ldots \ldots \ldots \ldots$

3.1.6 Future and external requirements $\ldots \ldots \ldots \ldots \ldots \ldots \ldots, 10$

3.2 EXTERNAL INTERFACE REQUIREMENTS $\ldots \ldots \ldots \ldots \ldots \ldots \ldots 11$

3.3 PERFORMANCE REQUIREMENTS $\ldots \ldots \ldots \ldots \ldots \ldots \ldots \ldots \ldots, 11$

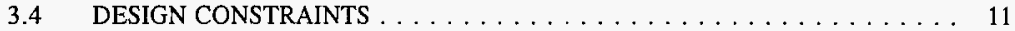

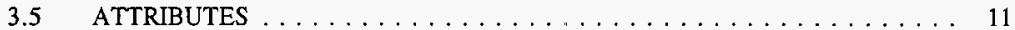

3.6 OTHER REQUIREMENTS $\ldots \ldots \ldots \ldots \ldots \ldots \ldots \ldots \ldots \ldots \ldots 11$

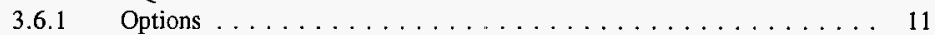

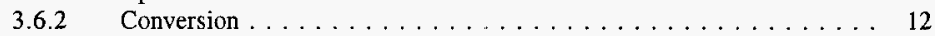

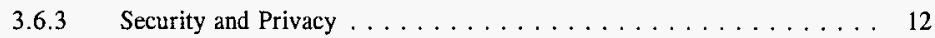

APPENDIX A

PAMS PHOTO FILE STRUCTURE $\ldots \ldots \ldots \ldots \ldots$ 


\subsection{INTRODUCTION}

This project is part of the Photo Audiovisual Management System (PAMS). The project was initially identified in 1989 and has since been has been worked on under various names such as "Image Retrieval \& Viewing System", "Photo Image Retrieval Subsystem" and "Image Processing and Compression System". This document builds upon the information collected and the analysis performed in the earlier phases of this project.

The PAMS Photo Imaging subsystem will provide the means of capturing low resolution digital images from Photography's negative files and associating the digital images with a record in the PAMS photo database. The digital images and key photo identification information will be accessible to HAN users to assist in locating and identifying specific photographs. After identifying desired photographs, users may request photo prints or high resolution digital images directly from Photography.

The digital images captured by this project are for identification purposes only and are not intended to be of sufficient quality for subsequent use.

\subsection{PURPOSE}

The purpose of this Requirements Document is to document the functional requirements for the PAMS Photo Image Retrieval Prototype.

\subsection{SCOPE}

This project will focus on identification, procurement, development and implementation of a photograph image retrieval subsystem of PAMS for Photography and Audiovisual Services.

\subsection{OVERVIEW}

Photography and Audiovisual Services uses a system called the Photography and Audiovisual Management System (PAMS) to perform order entry and billing services. The PAMS system utilizes Revelation Technologies database management software, AREV. Work is currently in progress to link the PAMS AREV system to a Microsoft SQL Server database engine to provide photograph indexing and query capabilities. The link between AREV and SQL Server will use a technique called "bonding."

This photograph imaging subsystem will interface to the PAMS system and handle the image capture and retrieval portions of the project. 


\subsection{DEFINITIONS}

Chrominance

Color depth

Composite video

Field (video)

Frame

Frame Grabber

HAN

JPEG

Luminance

NTSC

PAMS

Pixel

Resolution (frame)
The color component of a video signal carrying saturation and hue information. Abbreviated as " $\mathrm{C}$ ".

The amount of color information given to each pixel, measured in bits per pixel. The higher the bits per pixel, the more detailed and realistic are the displayed images. 8 -bits/pixel translates to 256 colors ( 2 to the 8 th power) and 24-bits/pixel translates to 16.7 million colors.

Analog video that combines the red, green and blue and synchronization information into a single signal transmitted on a single line.

One of two portions of the screen in an interlaced display.

A complete video image, equaling one odd field and one even field. NTSC has 30 frames per second, each frame has 525 scan lines (486 are displayed, the remaining are devoted to refresh and sync).

A circuit that captures one frame of video into special memory in real time (usually at up to 30 frames per second to match the NTSC rate). Inputs to a frame grabber board are typically a video camera, a Video Cassette Recorder (VCR) or a TV tuner.

\section{Hanford Area Network}

Joint Photographic Experts Group, usually refers to a proposed standard for still image compression and decompression. JPEG compression is a lossy compression in that information is lost when an image is compressed. The decompressed image will not be the same as the original. The amount of information lost during JPEG compression is controlled by the degree of compress (expressed as a ratio) and the particular implementation of the compression algorithm.

The black and white component of a video signal. The amount of luminance is directly related to light intensity or brightness. Abbreviated as "Y".

National Television Standards Committee; also an acronym for the television broadcast standard in North America, 525 lines interlaced at 60 fields (30 frames) per second.

Photo Audiovisual Management System.

Picture element, a discrete area of an image sampled for luminance at one or more wavelength bands.

Frame resolution is described in pixels (spatial resolution) and bits of color per pixel (chroma resolution). For example, the standard resolution of VGA 
is 640 horizontal pixels by 480 vertical pixels by 8 color bits per pixel ( 256 colors) and is usually expressed as $640 \times 480 \times 8$-bits.

Resolution (video) - Usually described in terms of luminance and chrominance bandwidth. Resolution can vary horizontally (from about 180 resolvable lines for VHS to 800 lines for a very good broadcast video monitor or camera) but remains constant vertically (486 visible lines in video).

RGB Red-Green-Blue, the additive method of displaying color. The relative portions of each color produce the final color.

Scanner Electronic device for converting an image such as a photograph into digital computer format.

SQL $\quad$ Structured query language.

Super VHS (S-VHS) An analog format for recording video. This format provides higher resolution than standard VHS and uses S-video signals.

S-video

Designed for high-end consumer video, this is a signal that separates luminance and chrominance $(\mathrm{Y} / \mathrm{C}$ ) information onto separate wires.

VGA Videographics adapter, the PC standard for color display. 


\subsection{GENERAL DESCRIPTION}

\section{$2.1 \quad$ PRODUCT FUNCTIONS}

The PAMS Photo Image Retrieval Prototype project will provide the following functions:

Function-001 Capture still images from photo sources

The image sources will be photo negatives and slides. Occasionally, photo prints and stills from video will be captured.

Both color and grayscale images will be captured.

Limited editing capabilities, such as mirroring the image and adjusting color and contrast, will be available during image capture process.

Digital images will be compressed before storing on database.

The capability to overlay text on captured images is desirable.

Function-002 Integrate with the PAMS photo negative database.

Photo identification and keyword information about photo negatives will be maintained in the PAMS database (PAMS PHOTO FILE). End users will query the PAMS database to locate photo images.

The image capture procedure must tightly integrate with the PAMS database record update procedure.

Function-003 Provide site wide retrieval of photo images

The capability to search for and retrieve the photo images shall be available to HAN users. A minimum standard workstation configuration will be identified.

Viewing of single or multiple images on a single screen will be available to users.

Desirable to allow each user to maintain a local file of selected images or pointers to the images.

Desirable to provide printing of images on standard HAN printers. Color images will be printed as grayscale on black/white printers.

Function-004 Perform System Administration

Access control.

Backup and recovery. 
Change control.

Database administration.

Configuration control of both Client and Server hardware and software.

\subsection{USER CHARACTERISTICS}

Users of this system will consist of Photography and Audiovisual Services and selected HAN users (approximately 24 users). Photography and Audiovisual Services will have a single station for image capture and storage (see section 3.1.3 for workstation requirements). HAN users will access the database with appropriate hardware and software to perform image retrieval (see section 3.1 .5 for retrieve workstation requirements). 


\subsection{SPECIFIC REQUIREMENTS}

\subsection{FUNCTIONAL REQUIREMENTS}

\subsubsection{Database Server}

This section describes the requirements for the database server and photo image storage. A server has already been obtained for the SQL database as part of the PAMS project.

- Record volume for the photo image database is expected to be 10,000 new records per year. No record purging is anticipated. Initial sizing of the file storage will be for five full years of operation.

- Images and text database shall be backed up (archived) for recovery purposes.

- The user has no preference of either magnetic or optical image storage media - although they do have two 12" Sony optical drives that will be available for use with this project (currently drives are being used by the ISEARCH project).

- A Microsoft SQL Server database engine has been procured for this project.

- The database record structure has been defined with exception of image location attributes. See appendix A for the structure of the database record.

The current structure consists of one record per image. The record has a 13 character compound key formed from a nine character and a four character field (see text overlay below for possible use of the key). There are forty four total fields in the record representing standard fixed length character fields, numeric fields and dates. Thirty two of the fields are indexed.

Other supporting tables have been defined for purposes of editing and field value lookup during record entry.

\subsubsection{Stored Image Attributes}

This section describes the important attributes for the stored images.

- A standard image resolution will be determined during the project design phase but is expected to be up to 320 pixels in either the horizontal or vertical direction.

- Both color and grayscale images will be captured.

- Color depth shall be 24-bit ( 8 bits per color of RGB) and the grayscale depth shall be 8-bit (256 shades).

- JPEG (compressed) is the preferred storage format for photo images. This technique provides lossy compression but is satisfactory for this project. 
n The compression ratio shall be software selectable. The actual ratio will be determined after sampling of images and is expected to be $20: 1$.

\subsubsection{Image Capture Workstation}

This section describes the requirements for the image capture workstation.

- Initially, photo images will be captured at a single scanning station located at the 3705 building in 300 Area.

- The station will be attached to HAN.

- A standard $486 / 33$ workstation configuration shall be used. The station shall utilize the standard core configuration and Windows 3.1 graphical user interface.

- The station shall have a Super VGA (SVGA) video monitor and video card capable of displaying 24 -bit color at a minimum $640 \times 480$ resolution. A $17^{\prime \prime}$ or larger video monitor is desirable.

- Initial reviews of capture products available indicate that certain other configuration items may be required. These include an ISA bus (IBM/AT compatible bus) and a feature connector for the video card.

\subsubsection{Image Capture}

This section describes the requirements for inputs, hardware and software to support the capture and processing of photo images.

- Image Sources are expected to be as follows:

95\% from Negatives

$3 \%$ from Slides

Less than $1 \%$ from Prints

Less than $1 \%$ Still frames from Video (NTSC Composite and Y/C)

Original sizes: $135,120(6 \times 4.5,6 \times 6,6 \times 7), 4 " \times 5 ", 5 " x 7 ", 8 " x 10^{\prime \prime}, 9 " x 9^{\prime \prime}$

- Based upon previous studies, the input method is recommended to be a still or video camera with capture board. The photography group will make an appropriate camera available for use by this project. The capture board shall support the following inputs:

- Composite NTSC

- S-Video (Y/C)

- RGB (desirable)

Software which also supports scanner input is desirable.

- It is desirable to have the capability for text overlay on the image at capture time (the text becomes part of stored image). This text is primarily intended to ensure that the photo id 
does not become separated from the digital image. Specific requirements include the following:

- Automatic overlay of the record key text. When an image is captured and associated with a record, the record key text (photo id and series number) should be automatically overlaid on the image.

- User control of text location on the image.

- User control of text color (to stand out from the image background).

- User control of other text characteristics such as font and size.

- While an image is being manipulated during capture, the image shall be displayed on the screen in a "what you see is what you get" fashion. For example, an image which the operator has asked to be software rotated will display on the screen in the correct rotation position. Other manipulations such as color changes, resolution changes and text overlay will display as performed.

- Entry of text record data shall be provided as follows:

- Create a text record concurrent with image capture. The PAMS system will provide this capability. For this portion of the system a means of automatically passing data to PAMS, such as Dynamic Data Exchange (DDE), will be developed. This method requires that PAMS and the image capture program operate simultaneously on the capture station and that a dialog be established between the two systems.

- For records already on file, image information will be added at time of image capture. The operator will enter the record key information to identify the photograph. Then the process will display the record data and, if approved by the operator, automatically update the image location data.

- Camera image correction features will be required to efficiently handle the various input formats. For the most part, images will be batched by format for input. Therefore, the process of capturing images will be simplified and faster if certain features can be set at the camera. These features include the following:

- Convert photo negatives to positives.

- Crop the image.

- $\quad$ Resize up and down (probably a zoom feature).

- Contrast adjustment.

- Exposure adjustment.

- Color correction.

- Some images will require corrections after being obtained from the camera and before committing to storage. These correction features can be implemented within the capture board (if under software control) or in the processing software itself. Correction features include the following: 
- Photo negative to positive translation.

- Crop image (only rectangular cropping is required).

- $\quad$ Resize image $\pm 50 \%$

- Contrast adjustment.

- Brightness adjustment.

- Color correction.

- Rotate the image. A 90 and 180 degree rotation is required, however, continuously variable rotations are desirable to handle skewed images.

- Mirror image left to right.

- Mirror image top to bottom.

- Color to grayscale conversion.

- JPEG compression/decompression of stored image. Can be hardware or software implemented.

- Capture at a predetermined standard resolution (software control of capture resolution).

- Response time of 10 seconds per image capture and record update.

\subsubsection{Retrieve Workstation}

This section describes the requirements for user retrieval of photo images.

- Initially, approximately 24 key users at various site locations will have access to the photo image database for retrieve purposes.

- The retrieve software must be compatible with the site's CORE workstation configuration. User interface will be a Windows 3.1 graphical user interface (GUI). User workstations are expected to have a minimum of 8-bit (256 color) VGA display and a desirable 24-bit display.

- SQL search against text portion of database. Any text record field(s) can be used in the record search. The results of a search will be both text records and their associated photo images. The user will have the option of displaying either or both of the data types.

The search query should be easy to formulate by a minimally trained end user.

Search operators of 'EQUAL', 'LIKE', 'LESS THAN', and 'GREATER THAN' will be provided. Because the results of a query are expected to return only a small number of possible photos, statements such as 'NOT EQUAL' and 'NOT LIKE' will not be available to the user.

Use of logical connections 'AND' and 'OR' will be provided to the user.

The non-normalized structure already defined for the data records uses separate fields for each 'KEYWORD' and each 'CHAR' (CHAR refers to names of individuals in the photo). Each record is limited to six KEYWORD's and five CHAR's. Any query involving KEYWORD or CHAR fields will be programmed to automatically 'OR' against all instances of these 
fields. That is, a search involving a KEYWORD will return a hit if the KEYWORD is in any of the six KEYWORD fields and similarly for a search for CHAR.

- Image viewing at a workstation shall meet the following:

- User selectable method of viewing found images as sets or one at a time. The number of images in a set will be determined at system design time but is expected to be six.

- Images displayed in sets will be automatically resized to a standard size.

- The user shall have the ability to page forward through selections.

- $\quad$ The user shall have the capability to enlarge a single frame from set (by double clicking for example).

- Because of limited network capacity, most images will be sent from the server to the workstation in compressed mode and automatically decompressed at the workstation. The decompression software will be provided as part of the retrieval application. Because software decompression will be used, the configuration of the workstation is expected to greatly affect the image decompression speed.

- It is desirable to provide a means of printing images (in grayscale) on standard network printers. The user should have control of the printed image size.

- Local storage of images in "albums" is desirable. Users should be allowed to create albums of photo images and add individual photos to an album. The user will store the photo image album locally.

- Download of images in not required (possible exception for local album storage).

- Response times: Retrieval and display of first set of images should be less than 30 seconds after sending a simple query. Software decompression of images is expected to be the largest response time variable because it is dependent upon the processing speed of the workstation.

- It is desirable to automate sending a request to photography for proofs (perhaps through ccmail).

\subsubsection{Future and external requirements}

No future requirements are identified at this time.

\subsection{EXTERNAL INTERFACE REQUIREMENTS}

Only the PAMS SQL Server data base is identified as an external interface requirement.

\subsection{PERFORMANCE REQUIREMENTS}


The image capture portion of the system should be available during the normal PAMS operating hours. The image retrieval portion of the system should be available during the normal workday hours.

Backup and recovery for the SQL database portion of the system has been specified by the PAMS requirements. The image portion of the system shall conform to the same requirements.

Specific response times are stated in the functional requirements above.

\subsection{DESIGN CONSTRAINTS}

The image retrieval portion of the system should follow the Windows GUI standards as closely as possible.

Because the image capture portion of the system will operate in concert with the PAMS system, it's operational characteristics (look and feel) should be designed to use common techniques where possible.

The most important design constraint is the common SQL Server database shared with PAMS.

\subsection{ATTRIBUTES}

No special attributes have been identified.

\subsection{OTHER REQUIREMENTS}

Because this project is considered a subproject to the ongoing PAMS development, most of the items usually included in this section are already specified for PAMS and, as such, are not required for this document.

\subsubsection{Options}

An alternatives analysis is expected to be the next step in this project. The analysis will evaluate the alternatives discovered and propose a solution. Based upon information currently available, the major alternative decisions appear to be as follows:

- Select appropriate input device(s) such as image capture boards, scanners and cameras. (The user has stated a preference for capture boards versus scanners). There are numerous capture boards available with varying specifications.

- Procure robust or low level image capture software.

- Procure or build database query and image retrieval software.

\subsubsection{Conversion}

Photography currently has approximately two million negatives and photographs on file. Capturing of digital images for these existing works is not required for this project. 


\subsubsection{Security and Privacy}

The ability to add, delete, or modify captured images will be controlled by PAMS.

No restriction, other than usual HAN access, is required for image viewing.

None of the image or text data has been identified as classified, sensitive or proprietary. 
APPENDIX A

PAMS PHOTO FILE STRUCTURE

\begin{tabular}{|c|c|}
\hline PHOTO_ID & $\operatorname{char}(9)$ \\
\hline CAPTUREED_DASH_NO & $\operatorname{char}(4)$ \\
\hline UPDT_BY & $\operatorname{char}(20)$ \\
\hline UPDT_DTE & datetime \\
\hline RELAT̄ED_DASH_NO & $\operatorname{char}(10)$ \\
\hline NEG_CNT & smallint \\
\hline LEAD_CODE & $\operatorname{char}(2)$ \\
\hline DTE_WRK_PRFMD & datetime \\
\hline CUST̄_NAM̄E & $\operatorname{char}(20)$ \\
\hline CONTR CODE & $\operatorname{char}(5)$ \\
\hline CONTACTT & $\operatorname{char}(20)$ \\
\hline BLDG_OFFCL_NO & $\operatorname{char}(11)$ \\
\hline BLDG_NAME & $\operatorname{char}(50)$ \\
\hline FAC_TYPE_CD & $\operatorname{char}(2)$ \\
\hline FAC_TYPE_DESC & $\operatorname{char}(30)$ \\
\hline AREA & $\operatorname{char}(6)$ \\
\hline CITY & $\operatorname{char}(25)$ \\
\hline STATE & $\operatorname{char}(2)$ \\
\hline SUBJ TYPE & $\operatorname{char}(20)$ \\
\hline STYLE & char(15) \\
\hline TECHNIQUE & $\operatorname{char}(15)$ \\
\hline SITE_FUNC & $\operatorname{char}(20)$ \\
\hline KYWD01 & $\operatorname{char}(20)$ \\
\hline KYWD02 & $\operatorname{char}(20)$ \\
\hline KYWD03 & $\operatorname{char}(20)$ \\
\hline KYWD04 & $\operatorname{char}(20)$ \\
\hline KYWD05 & $\operatorname{char}(20)$ \\
\hline KYWD06 & $\operatorname{char}(20)$ \\
\hline CHAR_NAME_01 & $\operatorname{char}(20)$ \\
\hline CHAR_NAME_02 & $\operatorname{char}(20)$ \\
\hline CHAR_NAME_03 & $\operatorname{char}(20)$ \\
\hline CHAR NAME 04 & $\operatorname{char}(20)$ \\
\hline CHAR NAME 05 & char $(20)$ \\
\hline FIRST_USED_FOR & $\operatorname{char}(15)$ \\
\hline IMPAC̄T FLG & $\operatorname{char}(1)$ \\
\hline RIDS & $\operatorname{char}(2)$ \\
\hline STORAGE_BOX & $\operatorname{char}(7)$ \\
\hline DTE_SHIPPED & datetime \\
\hline PROJ NO & $\operatorname{char}(10)$ \\
\hline PROJ_NAME & $\operatorname{char}(10)$ \\
\hline FILM TYPE & $\operatorname{char}(3)$ \\
\hline IMAGE POINTER & $\operatorname{char}(15)$ \\
\hline FOOTNOTE & $\operatorname{char}(80)$ \\
\hline FILM TYPE_DESC & $\operatorname{char}(30)$ \\
\hline
\end{tabular}




$$
\text { WHC-SD-WM-SDS-008, Rev. } 0
$$

PAMS Photo Imaging Requirements Document

Approvals

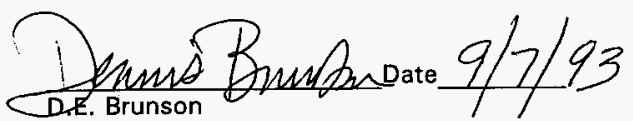

Photography \& Audiovisual Services, Mgr.

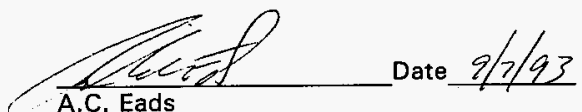

Photograhy \& Audiovisual Services

Date $8 / 31 / 93$

E.R. Carroll

Information \& Scientific Systems

M2Conven Date 8/30/93

M.L. Conner

Information \& Scientific Systems

$8 / 27 / 93$

Page 14 